\title{
Aerosol Delivery of Functionalized Gold Nanoparticles Target and Activate Dendritic Cells in a 3D Lung Cellular Model
}

\author{
Kleanthis Fytianos, ${ }^{\dagger}$ Savvina Chortarea, ${ }^{\dagger}$ Laura Rodriguez-Lorenzo, $^{\dagger}$ Fabian Blank, ${ }^{\S}$ \\ Christophe von Garnier, ${ }^{\S}$ Alke Petri-Fink, ${ }^{\dagger, \dagger}$ and Barbara Rothen-Rutishauser*, ${ }^{\dagger}$ \\ ${ }^{\dagger}$ Adolphe Merkle Institute and ${ }^{\ddagger}$ Department of Chemistry, University of Fribourg, CH-1700 Fribourg, Switzerland \\ ${ }^{\S}$ Respiratory Medicine, Inselspital, University of Bern, 3012 Bern, Switzerland
}

Supporting Information

\begin{abstract}
Nanocarrier design combined with pulmonary drug delivery holds great promise for the treatment of respiratory tract disorders. In particular, targeting of dendritic cells that are key immune cells to enhance or suppress an immune response in the lung is a promising approach for the treatment of allergic diseases. Fluorescently encoded poly(vinyl alcohol) (PVA)-coated gold nanoparticles, functionalized with either negative $\left(-\mathrm{COO}^{-}\right)$or positive $\left(-\mathrm{NH}_{3}^{+}\right)$surface charges, were functionalized with a DC-SIGN antibody on the particle surface, enabling binding to a dendritic cell surface

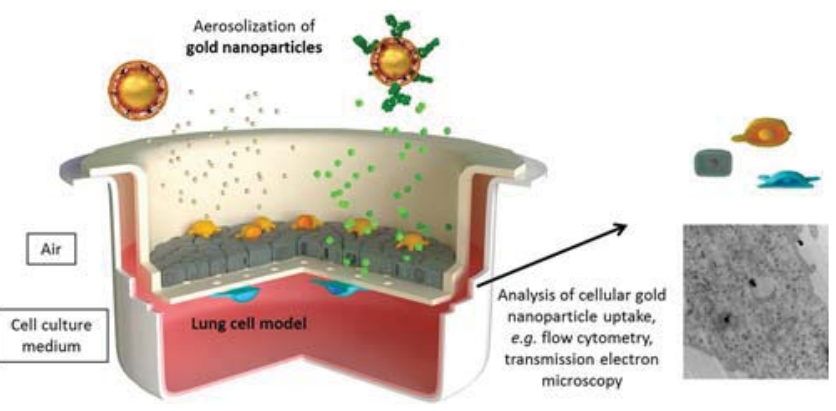
receptor. A 3D coculture model consisting of epithelial and immune cells (macrophages and dendritic cells) mimicking the human lung epithelial tissue barrier was employed to assess the effects of aerosolized AuNPs. PVA- $\mathrm{NH}_{2}$ AuNPs showed higher uptake compared to that of their $-\mathrm{COOH}$ counterparts, with the highest uptake recorded in macrophages, as shown by flow cytometry. None of the AuNPs induced cytotoxicity or necrosis or increased cytokine secretion, whereas only PVA- $\mathrm{NH}_{2}$ AuNPs induced higher apoptosis levels. DC-SIGN AuNPs showed significantly increased uptake by monocyte-derived dendritic cells (MDDCs) with subsequent activation compared to non-antibody-conjugated control AuNPs, independent of surface charge. Our results show that DCSIGN conjugation to the AuNPs enhanced MDDC targeting and activation in a complex 3D lung cell model. These findings highlight the potential of immunoengineering approaches to the targeting and activation of immune cells in the lung by nanocarriers.
\end{abstract}

KEYWORDS: gold nanoparticles, dendritic cells, aerosol exposures, cellular uptake, immunomodulation

$\mathrm{T}$ he human body has a number of portals of entry available for drug administration, such as the lungs (via inhalation), the gastrointestinal tract (via digestion), the blood vessels (via intravenous injection), and the skin (via transdermal application). The lung, with its huge internal surface of ca. $150 \mathrm{~m}^{2}$ (i.e., alveoli and airways), ${ }^{1}$ provides a promising, noninvasive portal of entry for aerosolized drugs. A number of inhaled drugs are currently applied to treat airway diseases, are in development, or have been considered for the treatment of various lung diseases. In 2004, there were about 25 drugs licensed for use in treating pulmonary diseases via inhalation, such as asthma, emphysema, chronic inflammation, chronic obstructive pulmonary disease (COPD), and lung cancer. $^{2}$

In addition to the large lung surface, areas of a dense network of antigen-presenting cell populations, such as dendritic cells (DCs) and macrophages, are present within the lung parenchyma. ${ }^{3}$ DCs are among the most important immune cells in the lung, orchestrating innate and adaptive immune responses. ${ }^{4}$ Specific targeting of DCs via receptor-mediated mechanisms has previously been described as an innovative approach to drug delivery. ${ }^{5,6}$ Dendritic cell-specific intracellular adhesion molecule 3 (ICAM-3)-grabbing non-integrin (DCSIGN) is a well-studied receptor that is found in abundance on the surface of mature DCs. It has a high affinity for mannose and is involved in the enhancement of antigen uptake, processing, and presentation to T-cells in the draining of lymph nodes. Targeting DC-SIGN may lead to the development of immunomodulatory applications such as a change in pro-inflammatory cytokine secretion. ${ }^{6}$ 

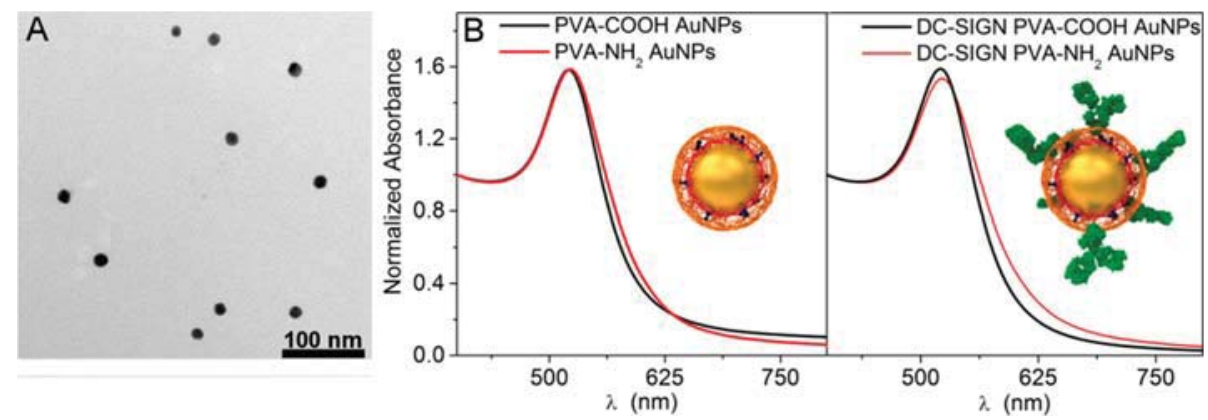

Figure 1. Characterization of AuNPs. TEM micrograph of $15 \mathrm{~nm}$ AuNPs (A) and UV-vis spectra (B) of the heterofunctionalized ATTO590 PVA-COOH and PVA-NH $\mathrm{N}_{2}$ AuNPs before and after DC-SIGN Ab conjugation. Inset: Schematic illustration of the designed AuNPs.

Table 1. Physicochemical Characterization of the Heterofunctionalized PVA-COOH and PVA-NH AuNPs $^{-}$

\begin{tabular}{|c|c|c|c|c|c|}
\hline AuNP sample & $\begin{array}{l}\text { hydrodynamic diameter }[\mathrm{nm}] \\
(\mathrm{PDI} \%)^{a}\end{array}$ & $\xi[\mathrm{mV}](\mathrm{SD})$ & $\begin{array}{l}\text { ATTO590 per } \\
\text { AuNP }^{b}\end{array}$ & $\underset{(\mathrm{SD})^{c}}{\operatorname{DC}}$ & $\begin{array}{c}\text { DC-SIGN per AuNP } \\
(\mathrm{SD})\end{array}$ \\
\hline PVA-COOH & $66(40)$ & $-13.6(9.2)$ & 720 & & \\
\hline PVA-NH ${ }_{2}$ & $111(38)$ & $10.6(3.2)$ & 350 & & \\
\hline DC-SIGN PVA-COOH & $100(42)$ & $-11.5(8.8)$ & 40 & $2.7(2.0)$ & $6(4)$ \\
\hline DC-SIGN PVA-NH ${ }_{2}$ & $175(49)$ & $8.6(3.1)$ & 28 & $0.7(0.5)$ & $2(1)$ \\
\hline
\end{tabular}

${ }^{a}$ At the 0.05 level, the difference between the population means is not significantly different. ${ }^{b}$ Fluorescence measured by means of Victor plate reader with the filter set to $560 / 615 .{ }^{c}$ Total protein estimation using Bradford assay.

The development of nanomaterials (i.e., a material with one, two, or three external dimensions in the nanoscale $(<100 \mathrm{~nm})$ (ISO/TS, 2008)) for drug delivery, medical imaging, and diagnostic purposes has led to the discovery of potential effective therapeutics. Depending on their size and properties, inhaled nanomaterials may enter the lung and interact with the respiratory wall. ${ }^{7,8}$ While larger materials are deposited in the conducting airways, smaller ones reach the peripheral gas exchange region and may pass the air-blood tissue barrier to enter the systemic circulation. The interaction with the lungs, and particularly the bioavailability of nanomaterials, depends on various nanomaterial characteristics, such as size, hydrophobicity, solubility, and enzymatic hydrolysis. Currently, nanomaterial-based (i.e., iron oxide, liposomes, polymer nanoparticles, emulsions, fullerenes, and carbon nanotubes) drugs are employed in biomedical applications due to their effectiveness in modulating immune responses., 90

Recently, our group has developed a library of homo- and heterofunctionalized, fluorescently labeled and polymer-coated gold nanoparticles (AuNPs). ${ }^{11}$ Fluorescently labeled nanoparticles (NPs) may be utilized for detection with techniques such as laser microscopy and flow cytometry, and the signals may be a useful tool for measurements such as cellular uptake and marker expression. ${ }^{12}$ Furthermore, AuNPs possess exceptional optical properties (scattering and absorption from localized surface plasmon resonances) and can be synthesized by rapid and highly reproducible methods. In addition, they are not cytotoxic at biomedically relevant concentrations. Using this NP library, we have shown that surface modification can alter cellular uptake, with the PVA- $\mathrm{NH}_{2}$ and PVA-COOH AuNPs being taken up by human blood monocyte-derived dendritic cells (MDDCs) in vitro, while functional and immunological properties were not impaired at concentrations of $20 \mu \mathrm{g} / \mathrm{mL}$. $^{13,14}$

In this study, we have further explored the potential of aerosolized PVA-COOH and PVA- $\mathrm{NH}_{2}$ AuNPs in terms of their cellular uptake and functional and immunological properties in an advanced in vitro coculture cell model representing the human lung epithelial tissue barrier ${ }^{15}$ under realistic exposure scenarios, that is, exposure of the AuNPs as an aerosol over the lung cell surface. Furthermore, the ability of DC-SIGN-conjugated AuNPs to specifically target MDDCs in the coculture model was investigated.

\section{RESULTS AND DISCUSSION}

AuNP Synthesis and Characterization. AuNPs were synthesized by the Turkevich method, ${ }^{16}$ coated with poly(vinyl alcohol) (PVA) with either a positive $\left(-\mathrm{NH}_{3}{ }^{+}\right)$or a negative $\left(-\mathrm{COO}^{-}\right)$charge and tagged with ATTO590 fluorescent molecules), as described by Rodriguez-Lorenzo et al.

It has been reported that the use of adequate conjugation strategies, in order to correctly orient the DC-SIGN antibody $(\mathrm{Ab})$, could strongly affect the accessibility of antigen binding sites. ${ }^{17-19}$ Therefore, the Ab conjugation was carried out by the fixed orientation of the $\mathrm{Ab}$ on the NP surface. In the case of PVA-COOH, the conjugation was achieved through ionic and covalent interactions as described by Parolo et al. ${ }^{46}$ The conjugation is based on the fact that when the $\mathrm{pH}$ of an $\mathrm{Ab}$ solution is lower than its isoelectric point, the concentration of positive charges $\left(-\mathrm{NH}_{3}{ }^{+}\right.$group of Lys residues) in the fragment-crystallizable region ( $\mathrm{Fc}$ region, which is the tail region of the $\mathrm{Ab}$ ) of the $\mathrm{Ab}$ is high. Therefore, negatively charged AuNPs $\left(\mathrm{COO}^{-}\right.$groups of PVA-COOH) most likely interact through the $\mathrm{Fc}$ region of the $\mathrm{Ab}$, and this oriented ionic attraction is bound via carbodiimide chemistry, guaranteeing that the antigen binding sites remain accessible. In contrast, the conjugation strategy of PVA- $\mathrm{NH}_{2}$ AuNPs consists of the use of the polysaccharidic region located in the $\mathrm{Fc}$ region of the $\mathrm{Ab}$ for covalent binding with amino group of the PVA-NH${ }_{2}$ polymer. ${ }^{17}$ Bradford assay measurements indicated that the concentration of $\mathrm{Ab}$ covalently bound to PVA-COOH was $2.7 \pm 2.0 \mu \mathrm{g}$, while that bound to PVA- $\mathrm{NH}_{2}$ was $0.7 \pm 0.5 \mu \mathrm{g}$, indicating that the conjugation was more efficient through peptide-bond formation than via the polysaccharidic region. It should be noted, however, that the number of ATTO590 molecules per AuNP decreased after $\mathrm{Ab}$ conjugation in both cases, which is most 
likely due to desorption of a part of the polymer layer during $\mathrm{Ab}$ conjugation.

Prior to employing the AuNPs in cell culture experiments, we thoroughly characterized both PVA-COOH and PVA- $\mathrm{NH}_{2}$ AuNPs by assessing their colloidal stability using UV-vis spectroscopy, their hydrodynamic radii, and polydispersity indices (PDI) using dynamic light scattering (DLS) and their surface charges through $\zeta$-potential measurements of AuNP suspensions in PBS. All AuNP types were stable and showed no evidence of aggregation-induced red shifting or band broadening in their UV-vis spectra (Figure 1B).

Analysis by DLS showed that DC-SIGN AuNPs presented hydrodynamic diameters higher than those of the unconjugated homologues: $100 \mathrm{~nm}$ versus $66 \mathrm{~nm}$ for PVA-COOH and 175 $\mathrm{nm}$ versus $111 \mathrm{~nm}$ for PVA- $\mathrm{NH}_{2}$ (Table 1). This increase may be attributed to the presence of $\mathrm{Ab}$, which can produce an increase up to $20 \mathrm{~nm}^{20}$ together with a swelling of polymer layer due to the variation of electrostatic interaction, as described in other studies. ${ }^{21,22}$ PVA-COOH AuNPs were negatively charged with a $\zeta$-potential of $-13.6 \pm 9.2 \mathrm{mV}$, and PVA- $\mathrm{NH}_{2}$ AuNPs were positively charged with a $\zeta$-potential of $10.6 \pm 3.2 \mathrm{mV}$ (Table 1).

Interestingly, the surface charge remained negative $(-11.5 \pm$ $8.6 \mathrm{mV})$ and positive $(8.6 \pm 3.1 \mathrm{mV})$ after $\mathrm{Ab}$ conjugation, which allowed a direct comparison of charged particles with and without $\mathrm{Ab}$ on cellular uptake patterns and MDDC-specific targeting potential and immunomodulatory effects.

AuNP suspensions $(120 \mu \mathrm{g} / \mathrm{mL})$ were prepared, and $1 \mathrm{~mL}$ was nebulized using the air-liquid interface cell exposure (ALICE) system. ${ }^{23}$ The deposited values on the bottom of the chamber were determined using a quartz crystal microbalance (QCM) and were $3.44 \pm 0.36$ and $4.34 \pm 0.42 \mu \mathrm{g} / \mathrm{cm}^{2}$ for the PVA-COOH and PVA- $\mathrm{NH}_{2}$, respectively, and $4.34 \pm 0.42$ and $6.17 \pm 0.19 \mu \mathrm{g} / \mathrm{cm}^{2}$ for the DC-SIGN AuNPs. TEM images (Figure S1) showed that AuNPs were monodisperse and that there was a uniform deposition after aerosolization.

Cellular Uptake. Four different AuNP types were used to study the interaction with the individual cell types in the coculture lung model. The particles were aerosolized over the lung cell surface, and cultures were post-incubated for $24 \mathrm{~h}$ before sample processing.

For flow cytometric analysis, cells were digested by trypsinEDTA and labeled for specific cell surface markers for multicolor detection as previously described (Clift et al., manuscript under revision). Particle uptake was measured as mean fluorescence intensity $(\triangle \mathrm{MFI})$ of ATTO590 from the $\mathrm{EpCAM}^{+}$cell population (A549 cells), CD80 (MDDCs), and $\mathrm{CD}_{11 \mathrm{a}^{+}}$(monocyte-derived macrophages, MDMs) (Figure 2).

For all three cell types, a low uptake of PVA-COOH was observed, whereas a significant increase in particle-positive MDMs was seen when the cultures were exposed to PVA- $\mathrm{NH}_{2}$ AuNPs. When DC-SIGN PVA-COOH particles were used, a significant increase in MDM-but also in MDDC-was observed as well as observation of more DC-SIGN PVA- $\mathrm{NH}_{2}$ AuNPs inside MDDCs than non-Ab-labeled ones. For epithelial cells, a generally low frequency of positive cells was observed for all four particle types.

TEM was used to qualitatively confirm the uptake of AuNPs, and the NPs were detected in all three cell types of the coculture (Figures 3 and S5). AuNPs were found in all different cell types either as single particles or as small agglomerates. Positively charged DC-SIGN AuNPs showed higher uptake levels in all cells compared to their negatively charged

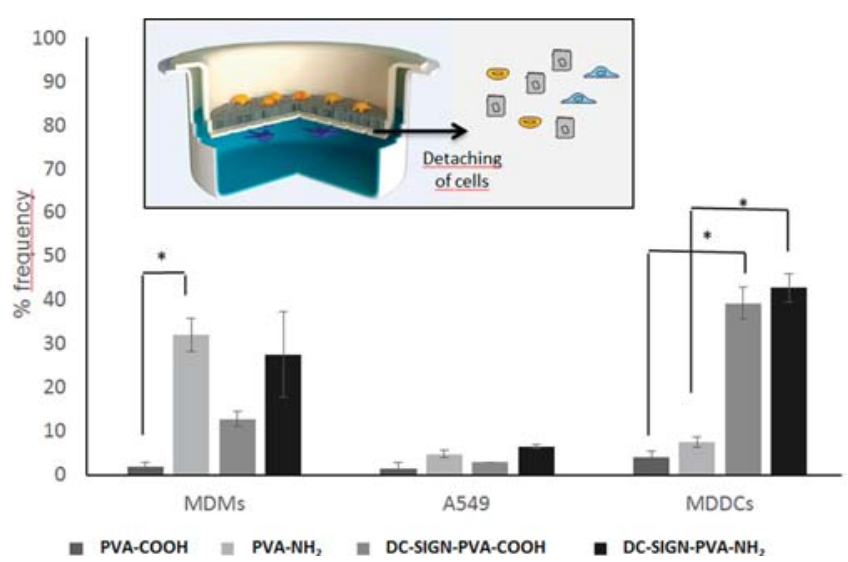

Figure 2. Cellular uptake of AuNPs in the cocultures. The cells grown on the membrane insert were detached from the inset after exposure to the AuNPs for $24 \mathrm{~h}$ (insert) and analyzed by flow cytometry. The three different cell populations were identified by the distinct cell surface markers that were used to label the cells. The MFI of ATTO590 was calculated for the three different cell populations that expressed these markers. Results indicated that PVA- $\mathrm{NH}_{2}$ AuNPs were predominantly taken up by the MDMs. DCSIGN-conjugated AuNPs showed an enhanced targeting of MDDCs. Each experiment was repeated three times, and cells from different cell cultures were obtained $\left(n=3,{ }^{*} p<0.05\right)$.

counterparts. Generally, AuNPs were found in all cell types either as single NPs, small or large agglomerates inside vesicles, or in the cytosol.

In addition to TEM, laser scanning microscopy images were obtained to show that the cell morphology and the epithelial monolayer structure were not impaired upon exposure to any of the AuNPs (Figure S4).

Cell Viability, Apoptosis, Cytotoxicity, and Cytokine Secretion. In the next step, the cell viability and induction of cell responses upon exposure to AuNPs was assessed. Only PVA- $\mathrm{NH}_{2}$ (i.e., non-DC-SIGN-PVA- $\mathrm{NH}_{2}$-functionalized) AuNPs significantly induced late apoptosis compared to the negative control (Figure 4). However, the PVA-NH $\mathrm{NH}_{2}$ polymer alone, which was used as a control, also induced significant late apoptosis levels. None of the AuNPs tested induced cytotoxicity, as shown by lactate dehydrogenase (LDH).

Considering cytokine secretion levels, enzyme-linked immunosorbent assay (ELISA) measurements showed no increase of release of various cytokines, such as IL- 8 , TNF- $\alpha$, and IL- $1 \beta$ (Figure 5), implying that none of the AuNP types tested interfere with the functional properties of the cocultures.

MDDC Surface Marker Expression. The surface marker expression of MDDCs was investigated by flow cytometry analysis. DC-SIGN-conjugated AuNPs of both surface functionalizations significantly upregulated MHC-II expression compared to the negative control (Figure 6).

AuNPs without DC-SIGN functionalization did not alter surface marker expression. In order to verify that the upregulated MHC-II expression can be attributed to the conjugated AuNPs and not to the antibody alone, DC-SIGN antibody suspensions at concentration levels of $2.7 \mu \mathrm{g} / \mathrm{mL}$ (a concentration level that corresponds to the AuNP suspensions) were aerosolized as a control measurement, and no effects were observed on surface marker expression (data not shown).

Specific Targeting Approach. Over the past few years, a significant amount of research has been conducted on drug delivery to the lungs by making use of NPs in aerosolized form, 

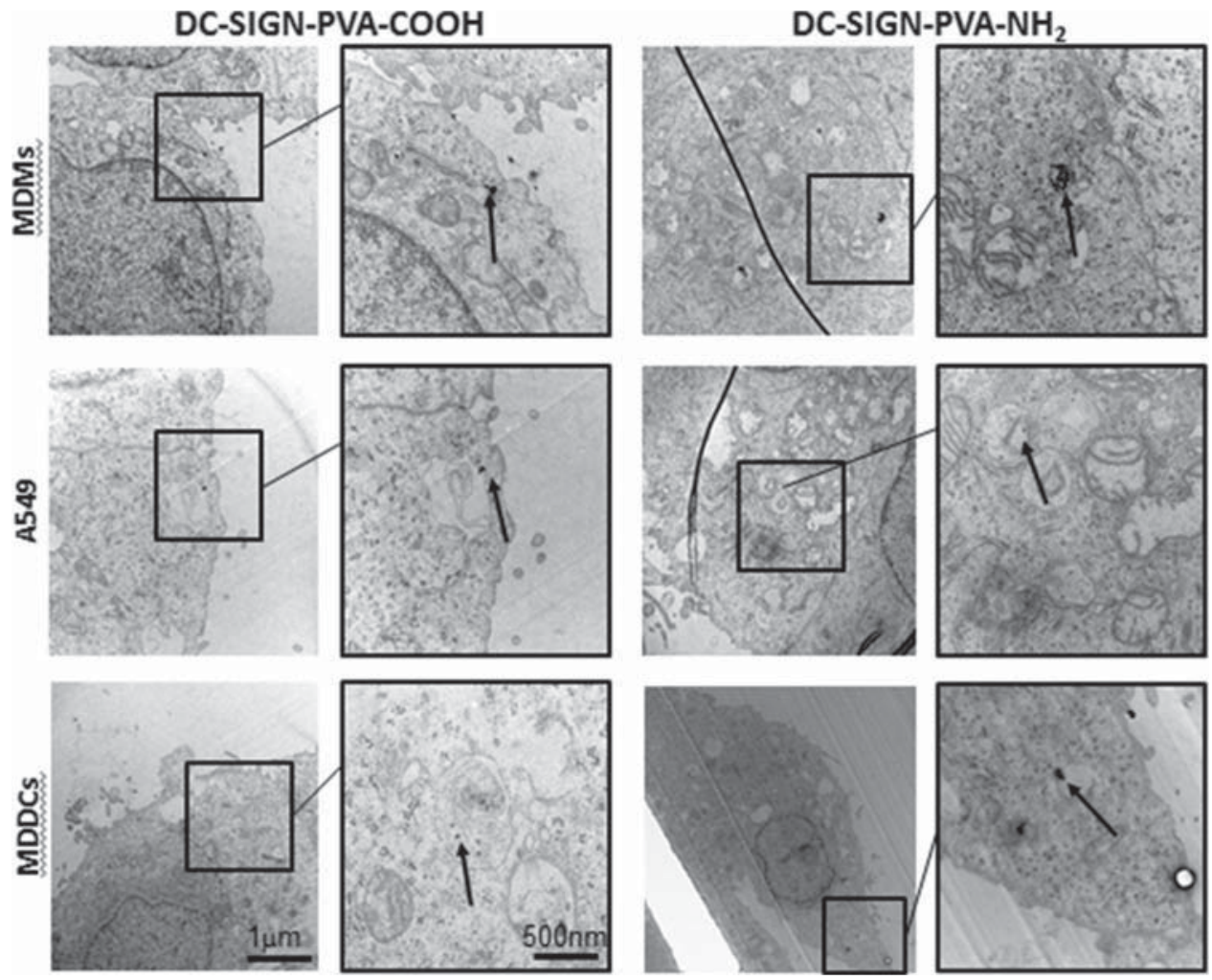

Figure 3. TEM micrographs. TEM images of internalized DC-SIGN AuNPs in MDMs, A549 (apical side of the 3D cocultures), and MDDCs

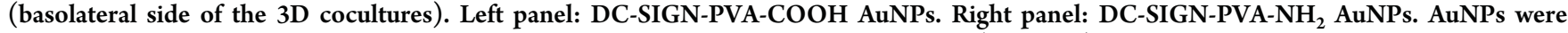
found inside cellular vesicles $24 \mathrm{~h}$ after exposure using the ALICE system. The boxes (overview) and zoomed-in images show the particles (arrows) (samples with lead citrate and uranyl acetate staining).

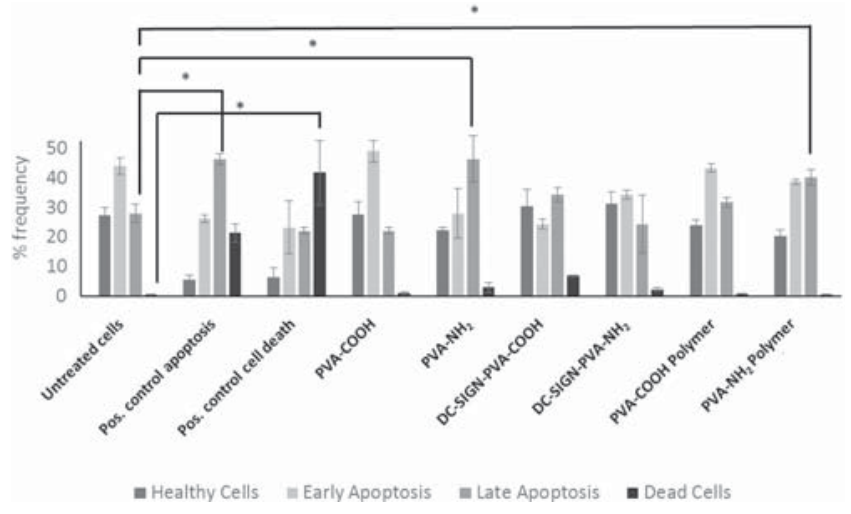

Figure 4. Apoptosis and cell viability. An Annexin V (apoptosis)/PI (cell death) assay was performed in order to determine the percentage of healthy, early and late apoptotic, and dead cells. PVA-COOH AuNPs did not influence cell viability, and when cells were exposed to PVA- $\mathrm{NH}_{2}$ AuNPs, a higher frequency of late apoptotic cells was recorded compared to the other treatments. Cells exposed to $2 \mathrm{mM}$ captothecin for $24 \mathrm{~h}$ were used as a positive control for apoptosis, and cells exposed to $-80{ }^{\circ} \mathrm{C}$ for $30 \mathrm{~min}$ were used as a positive control for cell death $(n=3, * p<0.05)$.

as reviewed by Müller and colleagues. ${ }^{24}$ Various types of NPs have proven capable of specific cell or organ targeting and sizespecific delivery. The aim of the study was to target MDDCs in vitro with aerosolized surface-modified AuNPs. By achieving this, an immune response might be triggered in vivo via crosstalk of pulsed DCs and T-cells.

We recently showed that AuNPs coated with PVA-COOH and PVA- $\mathrm{NH}_{2}$ were the NPs taken up by MDDCs at the highest numbers in monoculture suspensions, in comparison to AuNPs with polyethylene glycol surface modifications, ${ }^{11,13}$ compelling us to continue with more sophisticated experiments with these two particle types. PVA is an FDA-approved polymer that can improve colloidal stability, biocompatibility, and cell interactions both in vivo and in vitro. ${ }^{25-27}$ In the current study, we explore a more complex lung barrier model in order to further investigate the $\mathrm{NP}$-cell interaction and employ an air-liquid exposure system to aerosolize AuNPs. ${ }^{28}$ The tested AuNPs were aerosolized and shown to be uniformly deposited in the cell culture inserts, while also remaining monodisperse after aerosolization. The deposition of the particles was quantified by QCM, and we measured deposition values ranging from 3 to $6 \mu \mathrm{g} / \mathrm{cm}^{2}$ (Figure S1).

In order to investigate which cell types are taken up in the cocultures, we utilized a flow cytometry protocol where the insets from the cocultures were digested with trypsin/EDTA and the cell suspensions were stained with specific surface markers for each cell type. ${ }^{29}$ The results indicated that significantly more MDMs were measured with NPs for the positively charged particles (i.e., PVA- $\mathrm{NH}_{2}$ AuNPs) compared to negatively charged ones (i.e., PVA-COOH AuNPs). Similar results have been reported by Bachler et al. ${ }^{30}$ We also detected more NP-positive MDMs in comparison to epithelial cells and MDDCs. A similar pattern has also been observed by Seydoux and colleagues, wherein AuNPs with the same surface modification were mainly detected in the broncho-alveolar lavage macrophages in vivo. ${ }^{14} \mathrm{We}$ observed the presence of intracellular PVA-COOH particles by TEM imaging, and further research is ongoing to determine if the fluorophore 

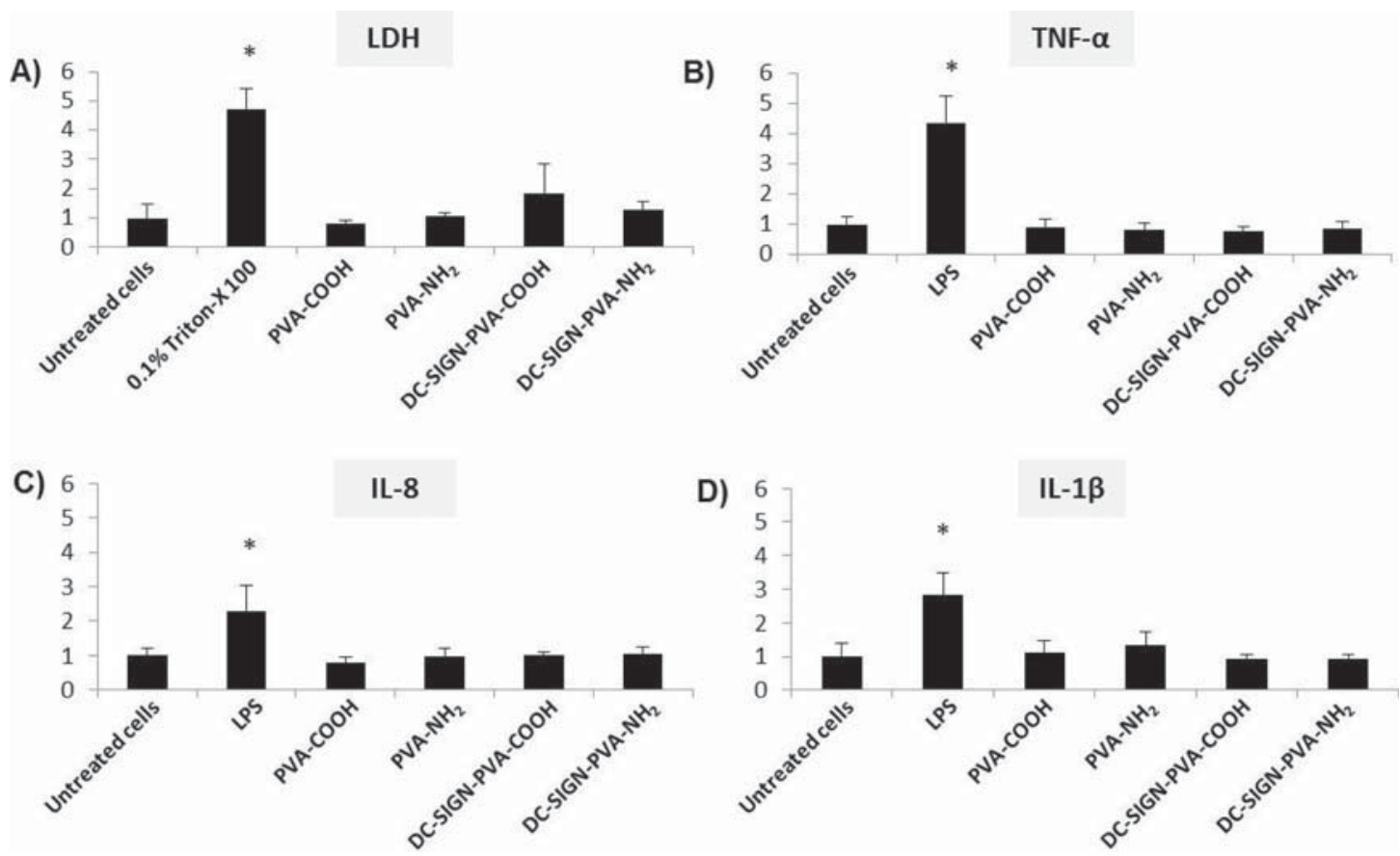

Figure 5. Cytotoxicity and cytokine secretion. Neither AuNP type elicited significant cytotoxicity levels, as indicated by LDH release (A). Inserts exposed to $\mathrm{dH}_{2} \mathrm{O} 0.9 \% \mathrm{NaCl}$ were used as negative controls, and inserts exposed to $0.2 \%$ Triton-X 100 (under submerged conditions) were used as positive controls. AuNP suspensions without cells were used as interference controls. At the given concentration levels $(20 \mu \mathrm{g} /$ $\mathrm{mL}$ ), no interference was measured. TNF- $\alpha(B)$, IL-8 (C), and IL-1 $\beta$ (D) secretion levels were at similar levels as the negative control (inserts exposed to $\mathrm{H}_{2} \mathrm{O}$ ), as measured by ELISA. Each $y$ axis is normalized to the respective negative control value. For all the cytokines tested, inserts exposed to $1 \mu \mathrm{g} / \mathrm{mL}$ LPS (under submerged conditions) were used as positive controls $(n=3, * p<0.05$ ).

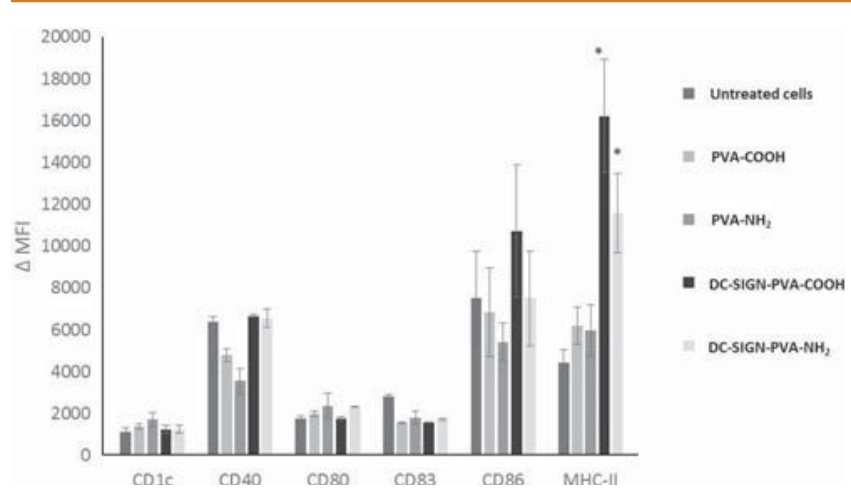

Figure 6. MDDC marker expression. The following MDDC surface markers were examined: CD1c, CD40, CD80, CD83, CD86, and MHC-II. AuNPs without DC-SIGN functionalization had no effect on the MDDC marker expression. In contrast, DC-SIGNconjugated AuNPs significantly upregulated MHC-II expression $(n=3, * p<0.05)$.

properties of ATTO590 in the polymer undergo quenching in an intracellular fashion.

Since our major aim was to establish a NP target and activate dendritic cells in the lung tissue, we conjugated DC-SIGN Ab onto the polymer surface of AuNPs. Both positively- and negatively charged DC-SIGN AuNPs were taken up by MDMs. In MDDCs, DC-SIGN-bound AuNP uptake was increased 4-5 fold compared to naked AuNPs, indicating that specific targeting of DCs is feasible.

Effect of AuNPs on the Functioning of MDDCs. None of the AuNPs tested had an effect on cytotoxicity and proinflammatory cytokine secretion. The AuNPs did not elicit significant LDH release, and the cytokine secretion levels were similar to those in negative control cells. These findings agree with the literature, which suggests that aerosolized AuNPs do not cause significant adverse effects, either in vitro or in vivo. ${ }^{15,23}$ We have recently shown that PVA-COOH and $\mathrm{PVA}-\mathrm{NH}_{2}$ AuNPs do not interfere with cytotoxicity and cytokine secretion in MDDC suspensions, at similar concentration levels and exposure times. ${ }^{13}$ After PVA- $\mathrm{NH}_{2}$ AuNP exposure corresponding to $3.44 \pm 0.36 \mu \mathrm{g} / \mathrm{cm}^{2}$ of deposited $\mathrm{Au}$ in the insets, the cells showed increased late apoptotic levels compared to the negative control. The apoptosis levels of the PVA-COOH AuNP-treated cells were similar to those of the negative control. In general, AuNPs can cause apoptosis only at very high concentrations. ${ }^{31,32}$ In order to clarify if the increased late apoptotic levels are due to the polymer itself, polymers without AuNPs were aerosolized in the ALICE, and the results indicated that the apoptosis pattern is observed due to the PVA-NH $\mathrm{N}_{2}$ polymer and not the AuNPs. Recently, we observed that aerosolized (PEG-PVA)- $\mathrm{NH}_{2}$ AuNPs led to increased apoptotic levels compared to the negative control after 3 days of repeated exposure. This means that apoptosis might be caused by the polymer coating $\left(\mathrm{PVA}-\mathrm{NH}_{2}\right)$ rather than the gold itself, and therefore, prolonged exposure to such biomedical particles needs to be studied in more detail (data not shown). Interestingly, we could show that when the polymer was shielded by the DC-SIGN Ab, the induction of late apoptosis decreased to control levels.

Considering immunological properties, the immunophenotyping marker expression remained unaltered in our study since CD1c expression was not impaired after AuNP exposure. The same applied for co-stimulatory markers such as CD40, CD80, and CD86. Considering activation marker expression, CD83 expression also remained unaltered, while MHC-II expression was significantly higher in MDDCs when the cocultures were 
exposed to DC-SIGN AuNPs compared to the negative control. This result highlights the immunomodulatory properties of the DC-SIGN-conjugated AuNPs. We have previously shown that MHC-II expression was not impaired after PVA$\mathrm{COOH}$ and PVA- $\mathrm{NH}_{2}$ AuNP exposure in suspension experiments using MDDM monocultures. Blank et al. ${ }^{33}$ observed increased MHC-II expression when MDDCs were exposed to superparamagnetic iron oxide NPs. MHC-II molecules are found in abundance on the surface of mature DCs. Increased MHC-II levels indicate that MDDCs have reached a maturation state. This might enable them to migrate to lymphoid tissues and interact with the $\mathrm{T}$-cell receptor $(\mathrm{TcR})$ of $\mathrm{CD} 4^{+} \mathrm{T}$-cells, thus influencing antigen presentation to $\mathrm{T}$-cells and initiating immune responses. ${ }^{34-37}$ Complementarily, Seydoux et al. ${ }^{14}$ have shown that cationic AuNPs that have been intranasally instilled can enhance antigen-specific $\mathrm{CD}^{+}{ }^{+} \mathrm{T}$-cell proliferation in the lung draining lymph nodes.

There is evidence in the literature for the utilization of DCSIGN AuNPs in biomedical applications. Arnaiz et al. ${ }^{38}$ synthesized $1.8 \mathrm{~nm}$ gold glyconanoparticles, some of which were internalized by immature DCs by both DC-SIGN- and non-DC-SIGN-mediated pathways, while the other part was colocalized with DC-SIGN receptors. This resulted in DCSIGN receptor blocking by these AuNPs and thus also inhibition of HIV-1 infection via T-cell communication crosstalk in vitro. Chiodo and colleagues ${ }^{6}$ engineered AuNPs conjugated to galactofuranose, a sugar which binds to the DC-SIGN receptor. These AuNPs induced pro-inflammation of MDDCs, as well as CD80, CD86, and HLA-DR upregulation. In addition, Arosio et al. ${ }^{39}$ synthesized AuNPs functionalized with $\alpha$-fucosylamide, a molecule which facilitated DC-SIGN receptor targeting. These AuNPs were internalized by MDDCs via the DC-SIGN receptor without triggering immune responses, thus they can be utilized for delivery purposes. Our results indicate that surface-modified AuNPs have great potential in the clinical field because, apart from their functional and immunomodulatory properties, they can also be cleared by alveolar macrophages. ${ }^{40}$

Another explanation of the increased MHC-II expression might be attributed to particle size. Cruz et al. ${ }^{41}$ demonstrated that nanosized poly(lactic-co-glycolic acid) particles were able to interact with DC-SIGN receptors of human DCs in vitro and elicit a significant $\mathrm{T}$-cell response compared to their microsized counterparts. Manolova and co-workers ${ }^{42}$ also demonstrated that the targeting efficacy (and thus immune response inductions) caused by virus-like particles $(30 \mathrm{~nm})$ also depends on the size of the particulate system, with smaller NPs being more potent than their larger counterparts $(200 \mathrm{~nm})$. DCSIGN is a well-studied receptor that is involved both in $\mathrm{CD}^{+}$ and $\mathrm{CD} 8^{+} \mathrm{T}$-cell stimulation. ${ }^{43}$ Vaccines that target DCs show considerable advantages and are considered a promising strategy for the further advancement of immunotherapy, as described by Kasternmüller et $a l^{43}$ and Kreutz et al. ${ }^{44}$ In this article, we investigate specific targeting of MDDCs by DCSIGN AuNPs in a complex 3D lung barrier coculture model. Sehgal et al., Cruz et al., and Arosio et al. ${ }^{39,41,45}$ tested DC targeting via the DC-SIGN receptor with polymer nanoparticles in DC monocultures in vitro. Efficient antigen uptake by DCs was observed, which resulted in enhanced T-cell targeting.

\section{CONCLUSION}

By applying an advanced 3D human lung model combined with air-liquid exposure of nanoparticles onto the cell surface and subsequent cellular analysis, we have shown that PVA- $\mathrm{NH}_{2}$ AuNPs were taken up mainly by MDMs, a finding which we confirmed in an animal study. ${ }^{14}$ When the particles were additionally functionalized with a DC-SIGN $\mathrm{Ab}$, the targeting of MDDCs present at the basal side of a 3D lung cell model was significantly enhanced. In addition, DC-SIGN AuNPs induced upregulation of MHC-II levels in the MDDC population, compared to the non-DC-SIGN-functionalized AuNPs. These findings demonstrate the effects of specific targeting of MDDCs via enhanced DC-SIGN AuNP uptake.

Our results demonstrate that there is potential for the development of pulmonary nanocarriers that can target lung DCs and elicit immune responses with this NP-based system. With our well-defined in vitro system, it is possible to identify the optimal NP candidate(s) for further in vivo experiments to test downstream immune reactions, such as activation of $\mathrm{T}$ cells, and also to determine if the particles are degraded, eliminated, or transferred to secondary organs.

\section{MATERIALS AND METHODS}

Synthesis and Characterization of AuNPs. PVA Coating of AuNPs. Carbodiimide chemistry was used to conjugate the primary amines of PVA- $\mathrm{NH}_{2}$ (M12, $M_{\mathrm{w}}=240000$, Erkol S.A., Spain) or the hydroxyl groups of both PVA (Mowiol 3-85, $M_{w}=15000$, Calbiochem, EMD Bioscience, Inc. La Jolla, CA, USA) and PVA$\mathrm{COOH}\left(\mathrm{KL} 506, M_{\mathrm{w}}=30000-50000\right.$, Kuraray Specialties Europe $\mathrm{GmbH}$, Hattersheim am Main, Germany) with the activated carboxyl groups of the ATTO590 NHS ester (Sigma-Aldrich, Buchs, Switzerland), as previously described by Rodriguez-Lorenzo et al. ${ }^{11}$ AuNPs $(15 \mathrm{~nm}$ in diameter, $[\mathrm{Au}]=0.5 \mathrm{mM})$ were synthesized following the protocol of Turkevich. ${ }^{16}$ In order to synthesize the PVA- $\mathrm{NH}_{2}$ and PVA-COOH AuNPs, PBS (1×, pH 7.4) solutions containing $8 \mathrm{mg}$ of dye-conjugated PVA- $\mathrm{NH}_{2}$ per $80 \mathrm{mg}$ of PVA (40\% ATTO590-PVA and $60 \%$ Mowiol 3-85 PVA) and $40 \mathrm{mg}$ of dye-conjugated $\mathrm{COOH}-$ PVA per $80 \mathrm{mg}$ of PVA (40\% ATTO590-PVA and 60\% Mowiol 4-88 PVA, $M_{\mathrm{w}}=30000$ ), respectively, were first prepared. Then, the respective polymer solution, which was previously sonicated for $1 \mathrm{~h}$ at $60{ }^{\circ} \mathrm{C}$, was added dropwise at RT with shaking to $48 \mathrm{~mL}$ of synthesized AuNPs. The mixture was incubated in the dark at RT for $24 \mathrm{~h}$ to reach thermodynamic equilibrium. Labeled, polymer-coated NPs were centrifuged $(10000 g, 1 \mathrm{~h})$ to remove excess polymer and redispersed in $40 \mathrm{~mL}$ of PBS $(1 \times, \mathrm{pH} 7.4)$. A second coating with unlabeled polymers (5 mg of $\mathrm{NH}_{2}-\mathrm{PVA} / 50 \mathrm{mg}$ Mowiol 3-85 for PVA$\mathrm{NH}_{2}$ AuNPs and $30 \mathrm{mg}$ of COOH-PVA/60 mg Mowiol 4-88 for COOH-PVA AuNPs) was then further applied using the same conditions. The samples were centrifuged at $10000 \mathrm{~g}$ for $1 \mathrm{~h}$ and redispersed in $1 \mathrm{~mL}$ of PBS (1×, pH 7.4).

DC-SIGN Antibody Conjugation to COOH-PVA AuNPs. The fixed orientation conjugation of the antibody to COOH-PVA AuNPs was carried out as previously reported by Parolo et al. ${ }^{46}$ with modifications. A solution of $20 \mu \mathrm{L}$ of $10 \mathrm{mg} / \mathrm{mL}$ EDC (TCI Europe) was mixed with $30.8 \mu \mathrm{L}$ of sulfo-NHS $(10 \mathrm{mg} / \mathrm{mL})$ at room temperature for $10 \mathrm{~min}$. Then, $53.8 \mu \mathrm{L}$ of a solution containing $3.7 \mathrm{mg} / \mathrm{mL}$ of EDC and 5.7 $\mathrm{mg} / \mathrm{mL}$ of sulfo-NHS (Sigma-Aldrich) was mixed with $0.5 \mathrm{mg}$ of PVA$\mathrm{COOH}$ AuNPs, and the total volume was increased to $800 \mu \mathrm{L}$ with MES buffer $(10 \mathrm{mM}, \mathrm{pH} 5)$. The resulting solution was incubated at $25{ }^{\circ} \mathrm{C}$ for $1 \mathrm{~h}$ with shaking to activate the carboxylic groups. The resulting activated PVA-COOH AuNPs were mixed with $5 \mu \mathrm{g}$ of DCSIGN antibody (Biolegend, cat. no. 343002) and left to react overnight at $4{ }^{\circ} \mathrm{C}$. After the incubation, $2 \mu \mathrm{L}$ of a $40 \mathrm{mM}$ solution of ethanolamine (Sigma-Aldrich) was added to the conjugated AuNPs, and these were incubated for $1 \mathrm{~h}$ to block the remaining activated $-\mathrm{COOH}$ group. The obtained conjugates were centrifuged at $10000 \mathrm{~g}$ for $1 \mathrm{~h}$. Finally, the resulting oriented DC-SIGN PVA-COOH AuNPs 
were redispersed in PBS (1×, pH 7.4), reaching a concentration of 450 $\mu \mathrm{g} / \mathrm{mL}$.

DC-SIGN Antibody Conjugation to PVA-NH $\mathrm{N}_{2}$ AuNPs. Conjugation via the polysaccharidic region of the $\mathrm{Ab}$ was carried out based on the procedure reported by Puertas et al. ${ }^{17}$ A solution containing $10 \mu \mathrm{g}$ of DC-SIGN antibody in $120 \mu \mathrm{L}$ of PBS (1×, pH 7.4) was incubated with $20 \mu \mathrm{L}$ of a $0.01 \mathrm{M} \mathrm{NaIO}_{4}$ aqueous solution for $3 \mathrm{~h}$ at $4{ }^{\circ} \mathrm{C}$ in the dark. Then, $5 \mu \mathrm{L}$ of glycerol was added to quench the reaction, and the mixture was left to react for $1 \mathrm{~h}$. The Ab solution was incubated with $0.5 \mathrm{mg}$ of PVA-NH $\mathrm{NH}_{2}\left(1.4 \mathrm{~mL}\right.$ of PBS) overnight at $4{ }^{\circ} \mathrm{C}$. The Schiff bases formed from the amine groups of the AuNPs and the aldehyde groups of the oxidized $\mathrm{Ab}$ were reduced by incubation with $7.7 \mu \mathrm{L}$ of $10 \mathrm{mM}$ sodium cyanoborohydride $\left(\mathrm{NaNCBH}_{3}\right.$, Sigma-Aldrich) and $162.87 \mu \mathrm{L}$ of $0.2 \mathrm{M}$ TRIS. The mixture was gently stirred at $25^{\circ} \mathrm{C}$ for $1 \mathrm{~h}$. The obtained conjugates were centrifuged at $10000 \mathrm{~g}$ for $1 \mathrm{~h}$. Finally, the resulting oriented-DC-SIGN PVA- $\mathrm{NH}_{2}$ AuNPs were redispersed in PBS (1×, pH 7.4), reaching a concentration of $315 \mu \mathrm{g} /$ $\mathrm{mL}$.

Particle Characterization Methods. UV-vis spectra of the samples were recorded at $37{ }^{\circ} \mathrm{C}$ using a Jasco V-670 spectrophotometer (Jasco Europe S.R.L., Milano, Italy), using $10 \mathrm{~mm}$ path length quartz cuvettes. Micrographs of the AuNPs were taken with a Tecnai Spirit transmission electron microscope (FEI), operating at $120 \mathrm{kV}$. The images were recorded at a resolution of $2048 \times 2048$ pixels (Veleta CCD camera, Olympus). The hydrodynamic radius was measured using a PBS solution containing $50 \mu \mathrm{g} / \mathrm{mL}$ AuNPs at $37^{\circ} \mathrm{C}$ by DLS at $90^{\circ}$ using a commercial goniometer instrument (3D LS spectrometer, LS Instruments AG, Switzerland). The surface charges of the AuNP samples were measured using $50 \mu \mathrm{g} / \mathrm{mL}$ suspensions in PBS at $25{ }^{\circ} \mathrm{C}$ using a phase amplitude light scattering (PALS) $\zeta$ potential analyzer (Brookhaven ZetaPALS). The Smoluchowski approximation was fitted to 20 cycles of electrophoretic mobility measurements, and 10 replicates were obtained for each sample to estimate the mean and the standard deviation (SD).

The $\mathrm{Ab}$ conjugation yield was determined using the Bradford protein concentration assay for both immobilization strategies. The AuNPs, after being conjugated with antibody, were centrifuged, and the supernatant was dialyzed against water to carry out the assay. A reference solution was prepared having exactly the initial $\mathrm{Ab}$ concentration under the same conditions. Therefore, the decrease in $\mathrm{Ab}$ concentration in the supernatant can be directly correlated with the amount of Ab conjugated on the AuNPs. The amount of ATTO590 on the AuNPs was determined by fluorescence using a PerkinElmer Victor microplate reader (560/615 filter set). Ten microliter samples of the AuNPs were dissolved with $10 \mu \mathrm{L}$ of $40 \mathrm{mM} \mathrm{KCN}$ (SigmaAldrich) to avoid any interference during the fluorescence measurements. All measurements were carried out in triplicate, and standard errors were never greater than 5\%. Finally, all AuNP types were tested for endotoxin contamination with the Pierce LAL chromogenic endotoxin quantification kit (cat. no. 88282, Thermo Scientific, Waltham, MA, USA) according to the manufacturer's instructions, and all AuNP types were found to have a value of $<0.5 \mathrm{EU} / \mathrm{mL}$.

Exposure Experiments. Air-Liquid Interface Cell Exposure. The ALICE is a well-established system that delivers aerosols in a dosecontrolled manner. It has been used to study the potentially hazardous effects of different types of nanomaterials ${ }^{23,47}$ and AuNPs. ${ }^{48}$ After nebulization of the AuNP suspensions onto the lung cell surface, cocultures were post-incubated for $24 \mathrm{~h}^{47} \mathrm{dH}_{2} \mathrm{O}$ containing $0.9 \%$ $\mathrm{NaCl}$ was used as control, with a QCM deposition value of $0 \mu \mathrm{g} / \mathrm{cm}^{2}$. The instrument's lowest limit of detection corresponds to $0.09 \mu \mathrm{g} /$ $\mathrm{cm}^{2}$.

Triple-Cell Coculture Model. Cocultures were prepared as previously described. ${ }^{15,49}$ Briefly, adenocarcinoma human alveolar basal epithelial cells (A549 cells) were grown under submerged conditions for 5 days on cell culture inserts (surface area of $4.2 \mathrm{~cm}^{2}$, pores with $3.0 \mu \mathrm{m}$ diameter, high pore density PET membranes for six-well plates (BD Biosciences, Basel, Switzerland; 353502) at a density of $1 \times 10^{6}$ cells $/ \mathrm{mL}$ ).

Monocytes were isolated from human buffy coat from healthy volunteers (Blood Donation Service, Bern University Hospital, Bern,
Switzerland) by gradient centrifugation (Lymphoprep, Axis Scield, Oslo, Norway) as previously described by Blank et al. ${ }^{9}$ and Fytianos et al. $^{13}$

Monocytes were differentiated into MDDCs by adding $10 \mathrm{ng} / \mathrm{mL}$ granulocyte-monocyte-colony stimulating factor and $10 \mathrm{ng} / \mathrm{mL}$ IL- 4 . MDMs were differentiated by adding $10 \mathrm{ng} / \mathrm{mL}$ monocyte-colony stimulating factor. Twenty-four hours after the assembly of the cocultures, cells were put into the air-liquid interface (ALI). Cells were maintained in ALI conditions for $24 \mathrm{~h}$ in order to produce surfactant, ${ }^{48}$ by removing the medium in the apical part and replacing the medium in the basolateral part with $1.2 \mathrm{~mL}$ of fresh medium.

Cellular Uptake of AuNPs. Flow Cytometry. The cellular uptake of aerosolized AuNPs within the individual cell types was measured as described in Clift et al. (manuscript under revision). Briefly, after exposure, inserts were treated with trypsin-EDTA $(0.5 \mathrm{~mL}$ in the upper and $1 \mathrm{~mL}$ in the lower part of the inset). After $2 \mathrm{~min}, 100 \mu \mathrm{L}$ of fetal calf serum was added to each part of the inset to inhibit trypsin activity. Cells were collected, washed with PBS, counted, and transferred to flow cytometry tubes at a density of $10^{6}$ cells $/ \mathrm{mL}$. They were stained with epithelial cell adhesion molecule EpCAM-APC (Biolegend, cat. no. 324208), CD80-FITC (Biolegend, cat. no. 305206), CD40-Pacific Blue (Biolegend, cat. no. 334320), and CD11a-PE-Cy7 (Biolegend, cat. no. 301220) at $4{ }^{\circ} \mathrm{C}$ for $30 \mathrm{~min}$. Cells were washed, and flow cytometric analysis was performed with a LSRFortessa instrument (BD Biosciences). All antibodies were diluted 1:50. All antibodies were purchased from Biolegend. For every measurement, 30000-50000 gated events were recorded. Figure S3 shows a detailed description of the gating strategy.

Transmission Electron Microscopy. In order to visualize the AuNPs after the nebulization process, TEM grids were integrated inside the exposure chamber and, after exposure, were left to dry in order to visually confirm uniform deposition of the AuNPs. Coculture samples were prepared as described by Chortarea et al. ${ }^{47}$ Briefly, after the exposure and $24 \mathrm{~h}$ incubation, inserts were fixed with $2.5 \%$ glutaraldehyde in HEPES buffer, then postfixed with $1 \%$ osmium tetroxide. This was followed by dehydration via graded ethanol series as well as Epon embedding. Finally, ultrathin sections of $50-80 \mathrm{~nm}$ were cut from the Epon, and samples were mounted on TEM grids. Images were taken using a TECNAI Spirit transmission electron microscope (FEI) operating at $120 \mathrm{kV}$. The images were recorded at a resolution of $2048 \times 2048$ pixels (Veleta CCD camera, Olympus).

Annexin V/Propidium lodide Assay. Apoptosis (Annexin V) and cell viability (propidium iodide) were measured with the Annexin V Fluos kit (Roche Diagnostics, Zug Switzerland; 11-828-681-001). Measurements were taken using a flow cytometer, and 10000 gated events were recorded. For positive controls, cocultures exposed to $\mathrm{dH}_{2} \mathrm{O} 0.9 \% \mathrm{NaCl}$ aerosol were digested and incubated with $2 \mu \mathrm{M}$ camptothecin (Sigma-Aldrich, cat. no. C9911-100MG) for $30 \mathrm{~min}$ or were cooled to $-80{ }^{\circ} \mathrm{C}$ for $30 \mathrm{~min}$, in order to induce apoptosis and necrosis, respectively. For negative controls, cocultures exposed to $\mathrm{dH}_{2} \mathrm{O} 0.9 \% \mathrm{NaCl}$ aerosol were digested and were not treated further. The gating strategy is shown in Figure S4.

Cytotoxicity and Cytokine Secretion. Supernatants in the basal cell culture chamber from the cocultures were collected and LDH (Roche Diagnostics, Zug Switzerland; 11-644-793-001) and ELISA were utilized to measure cytotoxicity and pro-inflammatory cytokine secretion, respectively. TNF- $\alpha$ (R\&D Systems, Abington, UK; DTA00C), IL-8 (R\&D Systems, Abington, UK; D8000C), and IL$1 \beta$ (R\&D Systems, Abington, UK; SLB50) secretion was measured according to the manufacturer's protocols. For negative controls, the supernatants from cocultures exposed to $\mathrm{dH}_{2} \mathrm{O} 0.9 \% \mathrm{NaCl}$ aerosol were collected. Then, $0.2 \%$ of Triton-X 100 and $1 \mu \mathrm{g} / \mathrm{mL}$ LPS were added under submerged conditions in the apical part of the insets, and the collected supernatants were used as positive controls for cytotoxicity and cytokine secretion, respectively.

MDDC Marker Expression. In order to measure potential immunomodulatory effects of the AuNPs on MDDCs, a MDDC surface marker expression study was conducted. The sample procedure was the same as that described in the Flow Cytometry section. Cells were stained with CD1c-APC-Cy7 (Biolegend, cat. no. 331520), 
CD40-Pacific Blue (Biolegend, cat. no. 334320), CD80-FITC (Biolegend, cat. no. 305206), CD83-biotinylated streptavidin-PE-Cy5 (eBioscience, cat. nos. 13-0839-80 and 15-4317-82), CD86-APC (Biolegend, cat. no. 305412), and MHC-II-PE-Cy7 (eBioscience, cat. no. 25-9952-41). The applied gating strategy was the same as described in the Flow Cytometry section.

Statistics. Results are presented as mean $(n=3$; i.e., independent experiments) \pm standard deviation. The Mann-Whitney U-test comparison for nonparametric data was utilized. The comparisons were performed using Microsoft Excel.

\section{ASSOCIATED CONTENT}

\section{(5) Supporting Information}

The Supporting Information is available free of charge on the ACS Publications website at DOI: 10.1021/acsnano.6b06061.

Figures $\mathrm{S} 1-\mathrm{S} 5$ as described in the text (PDF)

\section{AUTHOR INFORMATION}

\section{Corresponding Author}

*E-mail: barbara.rothen@unifr.ch. Phone: +41 263009502.

\section{ORCID ${ }^{\circ}$}

Kleanthis Fytianos: 0000-0002-7082-9493

\section{Notes}

The authors declare no competing financial interest.

\section{ACKNOWLEDGMENTS}

This study was supported by grants of the Swiss National Science Foundation (Grant Nos. 310030_159847/1 and 146249), the NRP 64 program "Opportunities and Risks of Nanomaterials", and the Adolphe Merkle Foundation.

\section{REFERENCES}

(1) Gehr, P.; Bachofen, M.; Weibel, E. R. The Normal Human Lung: Ultrastructure and Morphometric Estimation of Diffusion Capacity. Respir. Physiol. 1978, 32, 121-140.

(2) Patton, J. S.; Fishburn, C. S.; Weers, J. G. The Lungs as a Portal of Entry for Systemic Drug Delivery. Proc. Am. Thorac. Soc. 2004, 1 , 338-344.

(3) Holt, P. G.; Stumbles, P. A. Characterization of Dendritic Cell Populations in the Respiratory Tract. J. Aerosol Med. 2000, 13, 361367.

(4) von Garnier, C.; Nicod, L. P. Immunology Taught by Lung Dendritic Cells. Swiss Med. Wkly. 2009, 139, 186-192.

(5) Carrillo-Conde, B.; Song, E. H.; Chavez-Santoscoy, A. MannoseFunctionalized "Pathogen-like" Polyanhydride Nanoparticles Target C-type Lectin Receptors on Dendritic Cells. Mol. Pharmaceutics 2011, $8,1877-1886$.

(6) Chiodo, F.; Marradi, M.; Park, J. Galactofuranose-coated Gold Nanoparticles elicit a Pro-inflammatory Response in Human Monocyte-derived Dendritic Cells and are recognized by DC-SIGN. ACS Chem. Biol. 2014, 9, 383-389.

(7) Heyder, J.; Gebhart, J.; Rudolf, G.; Schiller, C. F.; Stahlhofen, W. Deposition of Particles in the Human Respiratory-Tract in the Size Range 0.005-15-Mu-M. J. Aerosol Sci. 1986, 17, 811-825.

(8) Patton, J.; Byron, P. R. Inhaling Medicines: Delivering Drugs to the Body through the Lungs. Nat. Rev. Drug Discovery 2007, 6, 67-74.

(9) Blank, F.; Gerber, P.; Rothen-Rutishauser, B.; Sakulkhu, U.; Salaklang, J.; De Peyer, K.; Gehr, P.; Nicod, L. P.; Hofmann, H.; Geiser, T.; Petri-Fink, A.; Von Garnier, C. Biomedical Nanoparticles Modulate Specific CD4+ T Cell Stimulation by Inhibition of Antigen Processing in Dendritic Cells. Nanotoxicology 2011, 5, 606.

(10) Smith, D. M.; Simon, J. K.; Baker, J. R. Applications of Nanotechnology for Immunology. Nat. Rev. Immunol. 2013, 13, 592605.
(11) Rodriguez-Lorenzo, L.; Fytianos, K.; Blank, F.; von Garnier, C.; Rothen-Rutishauser, B.; Petri-Fink, A. Fluorescence-Encoded Gold Nanoparticles: Library Design and Modulation of Cellular Uptake into Dendritic Cells. Small 2014, 10, 1341-1350.

(12) Vanhecke, D.; Rodriguez-Lorenzo, L.; Clift, M. J. D.; Blank, F.; Petri-Fink, A.; Rothen-Rutishauser, B. Quantification of Nanoparticles at the Single Cell Level - an Overview about State-of-the Art techniques and their Limitations. Nanomedicine (London, U. K.) 2014, 9, 1885-1900.

(13) Fytianos, K.; Rodriguez-Lorenzo, L.; Clift, M. J. D.; Vanhecke, D.; von Garnier, C.; Petri-Fink, A.; Rothen-Rutishauser, B. Uptake Efficiency of Surface Modified Gold Nanoparticles does not Correlate with Functional Changes and Cytokine Secretion in Human Dendritic Cells in Vitro. Nanomedicine (N. Y., NY, U. S.) 2015, 11, 633-644.

(14) Seydoux, E.; Rodriguez-Lorenzo, L.; Blom, R. A.; Stumbles, P. A.; Petri-Fink, A.; Rothen-Rutishauser, B. M.; Blank, F.; von Garnier, C. Pulmonary Delivery of Cationic Gold Nanoparticles Boost AntigenSpecific CD4+ T Cell Proliferation. Nanomedicine 2016, 12, 18151826.

(15) Rothen-Rutishauser, B.; Kiama, S. G.; Gehr, P. A ThreeDimensional Cellular Model of the Human Respiratory Tract to Study the Interaction with Particles. Am. J. Respir. Cell Mol. Biol. 2005, 32, 281-289.

(16) Enustun, B. V.; Turkevich, J. Coagulation of Colloidal Gold. J. Am. Chem. Soc. 1963, 85, 3317-3328.

(17) Puertas, S.; Moros, M.; Fernandez-Pacheco, R.; Ibarra, M. R.; Grazu, V.; de la Fuente, J. M. Designing Novel Nano-Immunoassays: Antibody orientation versus Sensitivity. J. Phys. D: Appl. Phys. 2010, 43, 474012 .

(18) Conde, J.; Dias, J. T.; Grazu, V.; Moros, M.; Baptista, P. V.; de la Fuente, J. M. Revisiting 30 years of Biofunctionalization and Surface Chemistry of Inorganic Nanoparticles for Nanomedicine. Front. Chem. 2014, 2, 00048.

(19) Marciello, M.; Filice, M.; Olea, D.; Velez, M.; Guisan, J. M.; Mateo, C. Useful Oriented Immobilization of Antibodies on Chimeric Magnetic Particles: Direct Correlation of Biomacromolecule Orientation with Biological Activity by AFM Studies. Langmuir 2014, 30, $15022-15030$.

(20) Lai, Y. H.; Koo, S.; Oh, S. H.; Driskell, E. A.; Driskell, J. D. Rapid Screening of Antibody-Antigen Binding using Dynamic Light Scattering (DLS) and Gold Nanoparticles. Anal. Methods 2015, 7, 7249.

(21) Khare, A. R.; Peppas, N. A. Swelling/Deswelling of Anionic Copolymer Gels. Biomaterials 1995, 16, 559-567.

(22) Skouri, R.; Schosseler, F.; Munch, J. P.; Candau, S. J. Swelling and Elastic Properties of Polyelectrolyte Gels. Macromolecules 1995, 28, 197-210.

(23) Lenz, A. G.; Karg, E.; Lentner, B.; Dittrich, V.; Brandenberger, C.; Rothen-Rutishauser, B. A Dose-Controlled System for Air-Liquid Interface Cell Exposure and Application to Zinc Oxide Nanoparticles. Part. Fibre Toxicol. 2009, 6, 32.

(24) Müller, L.; Lehmann, A. D.; Johnston, B. D.; Blank, F.; Wick, P.; Fink, A.; Rothen-Rutishauser, B. Inhalation Pathway as a Promising Portal of Entry: What Has To Be Considered in Designing New Nanomaterials for Biomedical Application? In Handbook of Nanotoxicology, Nanomedicine and Stem Cell Use in Toxicology, Sahu, S. C., Casciano, D. A., Eds.; John Wiley \& Sons, Ltd.: New York, 2014.

(25) Hirsch, V.; Kinnear, C.; Moniatte, M.; Rothen-Rutishauser, B.; Clift, M. J. D.; Fink, A. Surface Charge of Polymer Coated SPIONs Influences the Serum Protein Adsorption, Colloidal Stability and subsequent Cell Interaction. Nanoscale 2013, 5, 3723-3732.

(26) Alconcel, S. N. S.; Baas, A. S.; Maynard, H. D. FDA-approved Poly(ethylene glycol)-Protein conjugate Drugs. Polym. Chem. 2011, 2, 1442 .

(27) EFSA Opinion of the Scientific Panel on Food Additives, Flavourings, Processing Aids and Materials in Contact with Food on a request from the Commission related to the use of polyvinyl alcohol as a coating agent for food supplements, 2005; pp 1-5. 
(28) Brandenberger, C.; Rothen-Rutishauser, B.; Muhlfeld, C.; Schmid, O.; Ferron, G. A.; Maier, K. L. Effects and Uptake of Gold Nanoparticles Deposited at the Air-Liquid Interface of a Human Epithelial Airway Model. Toxicol. Appl. Pharmacol. 2009, 242, 56-65.

(29) Clift, M. J. D.; Fytianos, K.; Vanhecke, D.; Petri-Fink, A.; Rothen-Rutishauser, B. A Novel Technique To Determine the Cell Type Specific Response within an In Vitro Co-culture Model via Multi Color Flow Cytometry. Sci. Rep. 2016, submitted for publication.

(30) Bachler, G.; Losert, S.; Umehara, Y.; von Goetz, N.; RodriguezLorenzo, L.; Petri-Fink, A.; Rothen-Rutishauser, B.; Hungerbuehler, K. Translocation of Gold Nanoparticles across the Lung Epithelial Tissue Barrier: Combining In Vitro and In Silico Methods to Substitute In Vivo Experiments. Part. Fibre Toxicol. 2015, 12, 00908.

(31) Selim, M. E.; Hendi, A. A. Gold Nanoparticles Induce Apoptosis in MCF-7 Human Breast Cancer Cells. Asian. Pac. J. Cancer. Prev. 2012, 13, 1617-1620.

(32) Lan, M. Y.; Hsu, Y. B.; Hsu, C. H.; Ho, C. Y.; Lin, J. C.; Lee, S. W. Induction of Apoptosis by High-Dose Gold Nanoparticles in Nasopharyngeal Carcinoma Cells. Auris, Nasus, Larynx 2013, 40, 563568.

(33) Blank, F.; Gerber, P.; Rothen-Rutishauser, B.; Sakulkhu, U.; Salaklang, J.; de Peyer, K. Biomedical Nanoparticles Modulate Specific CD4+ T Cell Stimulation by Inhibition of Antigen Processing in Dendritic Cells. Nanotoxicology 2011, 1, 606.

(34) ten Broeke, T.; Wubbolts, R.; Stoorvogel, W. MHC Class II Antigen Presentation by Dendritic Cells Regulated through Endosomal Sorting. Cold Spring Harbor Perspect. Biol. 2013, 5, a016873.

(35) Villadangos, J. A.; Schnorrer, P.; Wilson, N. S. Control of MHC class II Antigen Presentation in Dendritic Cells: a Balance between Creative and Destructive Forces. Immunol. Rev. 2005, 207, 191-205. (36) Shin, J. S.; Ebersold, M.; Pypaert, M.; Delamarre, L.; Hartley, A.; Mellman, I. Surface Expression of MHC class II in Dendritic Cells is Controlled by Regulated Ubiquitination. Nature 2006, 444, 115-118. (37) Villadangos, J. A.; Cardoso, M.; Steptoe, R. J.; van Berkel, D.; Pooley, J.; Carbone, F. R; Shortman, K. MHC Class II Expression Is Regulated in Dendritic Cells Independently of Invariant Chain Degradation. Immunity 2001, 14, 739-749.

(38) Arnaiz, B.; Martinez-Avila, O.; Falcon-Perez, J. M.; Penades, S. Cellular Uptake of Gold Nanoparticles Bearing HIV gp120 Oligomannosides. Bioconjugate Chem. 2012, 23, 814-825.

(39) Arosio, D.; Chiodo, F.; Reina, J. J.; Marelli, M.; Penades, S.; van Kooyk, Y.; Garcia-Vallejo, J. J.; Bernardi, A. Effective Targeting of DCSIGN by $\alpha$-Fucosylamide Functionalized Gold Nanoparticles. Bioconjugate Chem. 2014, 25, 2244-2251.

(40) Balasubramanian, S. K.; Poh, K. W.; Ong, C. N.; Kreyling, W. G.; Ong, W. Y.; Yu, L. E. The Effect of Primary Particle Size on Biodistribution of Inhaled Gold Nano-agglomerates. Biomaterials 2013, 34, 5439-5452.

(41) Cruz, L. J.; Tacken, P. J.; Fokkink, R.; Joosten, B.; Stuart, M. C.; Albericio, F.; Torensma, R.; Figdor, C. G. Targeted PLGA Nano- but not Microparticles Specifically Deliver Antigen to Human Dendritic Cells via DC-SIGN In Vitro. J. Controlled Release 2010, 144, 118-126. (42) Manolova, V.; Flace, A.; Bauer, M.; Schwarz, K.; Saudan, P.; Bachmann, M. F. Nanoparticles Target Distinct Dendritic Cell Populations according to their Size. Eur. J. Immunol. 2008, 38, 1404-1413.

(43) Kastenmüller, W.; Kastenmüller, K.; Kurts, C.; Seder, R. A. Dendritic Cell-Targeted Vaccines - Hope or Hype? Nat. Rev. Immunol. 2014, 14, 705-711.

(44) Kreutz, M.; Tacken, P. J.; Figdor, C. G. Targeting Dendritic Cells-why bother? Blood 2013, 121, 2836-2844.

(45) Sehgal, K.; Ragheb, R.; Fahmy, T. M.; Dhodapkar, M. V.; Dhodapkar, K. M. Activation via IL-15-Dependent DC (DC) Subsets Leads to Enhanced T Cell Targeting of Multiple Human Dendritic Cell Nanoparticle-Mediated Combinatorial Crosstalk. J. Immunol. 2014, 193, 2297-2305.

(46) Parolo, C.; de la Escosura-Muniz, A.; Polo, E.; Grazu, V.; de la Fuente, J. M.; Merkoci, A. Design, Preparation, and Evaluation of a Fixed-Orientation Antibody/Gold-Nanoparticle Conjugate as an
Immunosensing Label. ACS Appl. Mater. Interfaces 2013, 5, 1075310759 .

(47) Chortarea, S.; Clift, M. J.; Vanhecke, D.; Endes, C.; Wick, P.; Petri-Fink, A.; Rothen-Rutishauser, B. Repeated Exposure to Carbon Nanotube-Based Aerosols does not affect the Functional Properties of a 3D Human Epithelial Airway Model. Nanotoxicology 2015, 9, 983.

(48) Brandenberger, C.; Muhlfeld, C.; Ali, Z.; Lenz, A. G.; Schmid, O.; Parak, W.; Gehr, P.; Rothen-Rutishauser, B. Quantitative Evaluation of Cellular Uptake and Trafficking of Plain and Polyethylene Glycol-Coated Gold Nanoparticles. Small 2010, 6, 1669-1678.

(49) Blank, F.; Rothen-Rutishauser, B.; Schurch, S.; Gehr, P. An Optimized In Vitro Model of the Respiratory Tract Wall to Study Particle Cell Interactions. J. Aerosol Med. 2006, 19, 392-405. 